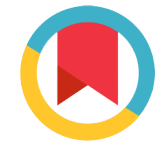

Check for updates
*For correspondence:

mozaffari20@yahoo.com

Competing interests: The authors declare that no competing interests exist.

Received: 01 September 2017 Accepted: 02 October 2017 Published: 14 October 2017

Copyright The Author(s) 2017. This article is published with open access by BioMedPress

This article is distributed under the terms of the Creative Commons Attribution License (CC-BY 4.0) which permits any use, distribution, and reproduction in any medium, provided the original author(s) and the source are credited.

\section{The Efficacy of Palifermin on Oral Mucositis and acute GVHD after Hematopoietic Stem Cell Transplantation in Hematologic Malignancy Patients: A Systematic Review and Meta-analysis study}

\section{Mehrdad Payandeh1, Masoud Sadeghi2,3 iD, Mazaher Ramezani4, Hamid Reza Mozaffari5,* (iD)}

\author{
${ }^{1}$ Department of Hematology and Medical Oncology, Kermanshah University of Medical \\ Sciences, Kermanshah, Iran \\ ${ }^{2}$ Medical Biology Research Center, Kermanshah University of Medical Sciences, \\ Kermanshah, Iran \\ ${ }^{3}$ Students Research Committee, Kermanshah University of Medical Sciences, \\ Kermanshah, Iran \\ ${ }^{4}$ Molecular Pathology Research Center, Emam Reza Hospital, Kermanshah University of \\ Medical Sciences, Kermanshah, Iran \\ ${ }^{5}$ Department of Oral and Maxillofacial Medicine, School of Dentistry, Kermanshah \\ University of Medical Sciences, Kermanshah, Iran
}

\section{Abstract}

Oral mucositis (OM) is one of the most common side effects after hematopoietic stem cell transplantation (HSCT) and palifermin is used for prophylactic use to prevent OM. We conducted a meta-analysis study that evaluates the efficacy of palifermin on OM after HSCT in hematologic malignancy patients. Databases of PubMed/Medline, Web of Science and Cochrane Library for English-language publications were searched for finding the relevant studies. The RevMan 5.3 software with random-effects models (odds ratio (ORs) and 95\% confidence intervals $(\mathrm{Cls})$ ) was used for to estimate of the efficacy of palifermin in palifermin group compared with control group. Begg's and Egger's tests were used for assessment of bias between the studies. Ten studies were included in the meta-analysis study. The results of the meta-analyses showed that there were significant differences in $\mathrm{OM}$ (grade 1-4) [odds ratio $(\mathrm{OR})=0.17 ; 95 \% \mathrm{Cl}=0.10,0.29 ; \mathrm{p}<0.00001$ ], $\mathrm{OM}$ (grade 2-4) $[\mathrm{OR}=0.11 ; 95 \% \mathrm{Cl}=0.05,0.24 ; \mathrm{p}<0.00001]$, OM (grade 3 -4) $[\mathrm{OR}=0.22$; $95 \% \mathrm{Cl}=0.15,0.33 ; p<0.00001]$, after auto-HSCT for OM (grade $1-4)[\mathrm{OR}=0.13 ; 95 \% \mathrm{Cl}=$ $0.04,0.35 ; p<0.0001]$, OM (grade 2-4) $[\mathrm{OR}=0.03 ; 95 \% \mathrm{Cl}=0.00,0.21 ; \mathrm{p}=0.0006]$ or $\mathrm{OM}$ 
(grade 3-4) $[\mathrm{OR}=0.25 ; 95 \% \mathrm{Cl}=0.13,0.48 ; \mathrm{p}<0.0001]$, after allo-HSCT for OM (grade $1-4)[\mathrm{OR}=0.23 ; 95 \% \mathrm{Cl}=0.11,0.51 ; p=0.0002]$, $\mathrm{OM}$ (grade $2-4)[\mathrm{OR}=0.14 ; 95 \% \mathrm{Cl}=$ $0.03,0.74 ; p=0.012]$ or $\mathrm{OM}$ (grade $3-4$ ) $[\mathrm{OR}=0.19 ; 95 \% \mathrm{Cl}=0.08,0.46 ; p=0.0002]$ and fever $[O R=0.51 ; 95 \% \mathrm{Cl}=0.29,0.87 ; p=0.01]$, but there were no significant differences in acute graft versus host disease (aGVHD) grades, infection and blood stream infection between two groups. The meta-analysis showed that palifermin was associated with reductions in the incidence and severity of $\mathrm{OM}$ and also was effective and safe on OM after allo- or auto-HSCT, but did not seem to effect on the incidence and severity of aGVHD.

\section{Keywords}

Hematologic Malignancy, Oral Mucositis, Palifermin, Stem Cell Transplantation

\section{Introduction}

Hematopoietic stem cell transplantation (HSCT) with high-dose chemoradiotherapy is frequently used in the treatment of patients with hematologic malignancies. During the conditioning regimen for HSCT (which includes total body irradiation or high dose chemotherapy), and immediately after the transplant, patients may present a variety of symptoms (Lauritano et al., 2014). Oral mucositis (OM) as one of symptoms of HSCT, is a common and important adverse effect (Filicko et al., 2003; Jilani et al., 2014; Radtke and Kolesar, 2005) and $\mathrm{OM}$ creates in approximately $70-80 \%$ of patients receiving radiation-based conditioning regimens (Epstein et al., 2012). The European Group for Blood and Marrow Transplantation (EBMT) Registry reported that there were annually around 23500 transplants including $38 \%$ of allogeneic SCT (allo-SCT) and $62 \%$ of autologous SCT (auto-SCT) (Hołowiecki, 2008). Allo-SCT is a form of immunotherapy and as one of HSCT types has increased survival of patients with relapsed leukemia and high-risk leukemia in remission that graft versus host disease (GVHD) was one of the most important complaints involving vital organs and infections (Kolb, 2017). Auto-SCT that is another HSCT type has become a well-established treatment for a variety of cancers (Vitale et al., 2014). Severe mucositis may create pain requiring opioid analgesics, a higher risk of infection, total parenteral nutrition, increased hospital charges, and decreased quality of life in the patients (Horsley et al., 2007). The incidence of severe OM in patients receiving high-dose myeloablative therapy with HSCT is $70-80 \%$ (Woo et al., 1993). This incidence in pediatric patients is higher than adults (Sonis and Clark, 1991). Palifermin as a recombinant human keratinocyte growth factor was approved in the European Union in October 2005 for prophylactic purpose to prevent severe OM in patients receiving high-dose therapy and auto-HSCT 
(Jilani et al., 2014; Czyzewski et al., 2014; Kobbe et al., 2010). In patients with hematologic cancer, a palifermin dosage of $60 \mu \mathrm{g} / \mathrm{kg} /$ day (total six doses, three doses before the preparative regimen and three doses after the stem-cell infusion), significantly decreases the incidence and duration of severe OM that this setting has been confirmed by the Food and Drug Administration (FDA) (Spielberger et al., 2004; Stiff et al., 2006). The aim of this meta-analysis study was to evaluate the efficacy of palifermin on the incidence and severity of OM and acute GVHD after HSCT in hematologic malignancy patients in case-control or matched-control studies.

\section{Materials and Methods}

\section{Search strategies}

A comprehensive search was done with search terms included with "palifermin" and "hematopoietic stem cell transplantation or HSCT or stem-cell transplant or stem cell transplant or hematopoietic cell transplantation or HCT or hematopoietic stem cell transplant or stem cell transplantation or stem-cell transplantation or hematopoietic stem-cell transplantation" and "oral mucositis or mucositis" in databases of PubMed/Medline, Web of Science and Cochrane Library for English-language publications.

\section{Study selection}

Three authors revised selection of the studies. The first author (M.S) searched the studies and then the second author (M.R) blinded to the first reviewer. If there was any disagreement between the two authors, the third author (H.R.M) resolved the problem. All the articles of this study were examined for evaluation of the efficacy of palifermin on OM and/or aGVHD after HSCT in palifermin group compared with control group. The studies of this meta-analysis had to include the following inclusion criteria: a) case-control and control-matched studies (cohort, retrospective and non-randomized trial studies); b) human studies; c) the comparison of aGVHD and OM based on the World Health Organization (WHO) in two groups after HSCT; d) the studies reporting OM and/ or aGVHD in hematologic malignancies patients. Exclusion criteria: a) duplication of previous publications; b) the review and case series studies; c) randomized trial studies; d) the studies reporting OM and/or aGVHD in solid tumor patients.

\section{Data Extraction}

We collected the name of author, the year of publication, country, the number of patients in palifermin group, the number of patients in control group, age (range) of both groups, the percentage of the male in each group, the dose of 
palifermin and the type of HSCT for each study that met our criteria. The aGVHD and OM were graded according to the World Health Organization (WHO).

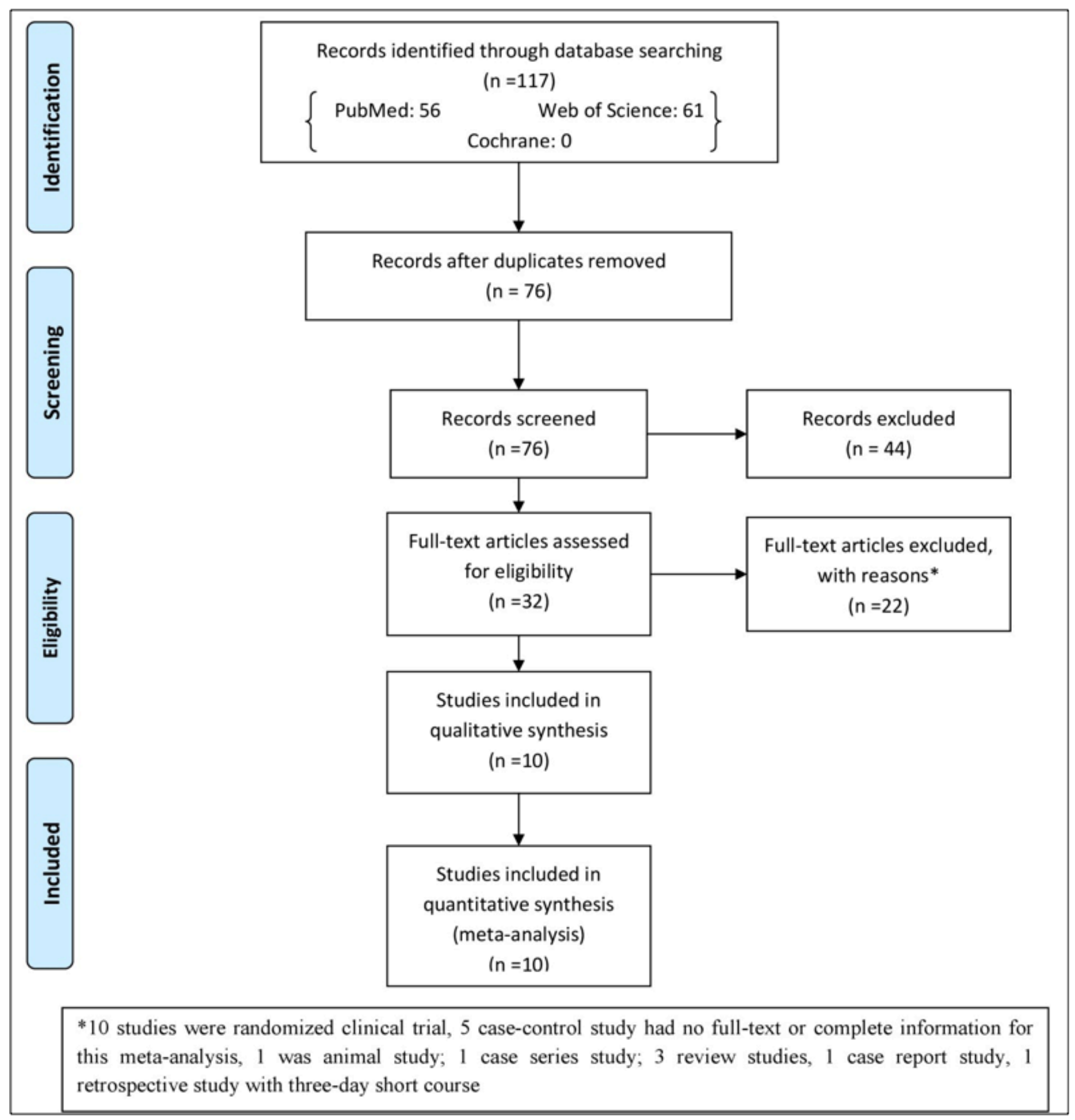

Figure 1. Flow chart for selection of the studies. 


\section{Statistical analyses}

The data analysis (a random-effect model) was done by Review Manager 5.3 (RevMan 5.3, The Cochrane Collaboration, Oxford, United Kingdom) using odds ratio (OR) and $95 \%$ confidence intervals $(\mathrm{Cls})$. The heterogeneity between estimations was calculated by the $\mathrm{Q}$ and $\mathrm{I}^{2}$ statistics that for the $\mathrm{Q}$ statistic, heterogeneity was considered for $p<0.1$. The $\mathrm{I}^{2}$ statistic yields results ranging from 0 to $100 \%(0-25 \%, 25-50 \%, 50-75 \%$ and $75-100 \%$ showed no heterogeneity, moderate heterogeneity, large heterogeneity and extreme heterogeneity, respectively (Egger et al., 1997). We graphically evaluated publication bias using funnel plots and quantitatively evaluated bias using Begg's and Egger's tests. $P<0.05$ (two-sided) was considered indicative of statistically significant publication bias.

Table 1. The characteristics of the studies included in the meta-analysis $(n=10)$

\begin{tabular}{|c|c|c|c|c|c|c|c|c|c|c|}
\hline \multirow[b]{2}{*}{ Study (years) } & \multirow[b]{2}{*}{ Country } & \multirow[b]{2}{*}{$\begin{array}{l}\text { Design } \\
\text { study }\end{array}$} & \multirow[b]{2}{*}{ Cancer } & \multicolumn{3}{|c|}{ Control Group } & \multicolumn{3}{|c|}{ Palifermin Group } & \multirow{2}{*}{$\begin{array}{c}\text { Type } \\
\text { of } \\
\text { HSCT }\end{array}$} \\
\hline & & & & $\mathbf{N}$ & $\begin{array}{c}\text { Age } \\
\text { (range), } \\
\text { years }\end{array}$ & $\begin{array}{c}\text { Male } \\
(\%)\end{array}$ & $\mathbf{N}$ & $\begin{array}{c}\text { Age } \\
\text { (range), } \\
\text { years }\end{array}$ & $\begin{array}{l}\text { Male } \\
(\%)\end{array}$ & \\
\hline Nguyen et al., 2015 & USA & $\mathrm{CC}$ & $\mathrm{HM}$ & 30 & $\begin{array}{c}34.3 \# \\
(18.5-56.7)\end{array}$ & 67 & 99 & $\begin{array}{c}42 \# \\
(18-59.2)\end{array}$ & 51 & Allo \\
\hline Czyzewski et al., 2014 & Poland & $\mathrm{MC}$ & $\mathrm{HM}$ & 31 & 13.2\# & 50 & 31 & $10.4 \#$ & 61.2 & Auto \\
\hline Herbers et al., 2014 & $\begin{array}{l}\text { Netherl } \\
\text { ands }\end{array}$ & $\mathrm{MC}$ & $\begin{array}{l}\text { Lympho } \\
\text { ma }\end{array}$ & 21 & $49 \$(23-64)$ & 81 & 23 & $\begin{array}{c}46 \$ \\
(18-65)\end{array}$ & 74 & Auto \\
\hline Lauritano et al., 2014 & Italy & $\mathrm{CC}$ & ALL & 20 & $11 \#(7.16)$ & 50 & 20 & $11 \#(7.16)$ & 55 & Allo \\
\hline Vitale et al., 2014 & USA & $\mathrm{CC}$ & $\mathrm{HM}$ & 33 & $6.8 \$$ & 60.6 & 25 & $7.9 \$$ & 56 & Auto \\
\hline $\begin{array}{l}\text { Nasilowska-Adamska et } \\
\text { al., } 2011\end{array}$ & Poland & $\mathrm{MC}$ & $\mathrm{HM}$ & 36 & $\begin{array}{l}35.5 \# \\
(18-64)\end{array}$ & 61.2 & 36 & $\begin{array}{c}37.5 \# \\
(19-63)\end{array}$ & 63.9 & Allo \\
\hline Langner et al., 2008 & Austria & $\mathrm{CC}$ & $\begin{array}{l}\text { Leukemi } \\
\quad \mathrm{a}\end{array}$ & 30 & 40\# (26-53) & 70 & 30 & $\begin{array}{c}37 \# \\
(18-59)\end{array}$ & 57 & Allo \\
\hline Tsirigotis et al., 2008 & Greece & $\mathrm{CC}$ & $\mathrm{HM}$ & 20 & $41 \$(24-65)$ & 55 & 15 & $\begin{array}{c}47 \$ \\
(24.69)\end{array}$ & 40 & Auto \\
\hline $\begin{array}{l}\text { Nasilowska-Adamska et } \\
\text { al., } 2007\end{array}$ & Poland & $\mathrm{CC}$ & $\mathrm{HM}$ & 53 & $\begin{array}{c}36.1 \# \\
(18-64)\end{array}$ & 49.1 & 53 & $\begin{array}{c}37 \# \\
(19-58)\end{array}$ & 49.1 & $\begin{array}{l}\text { Allo } \\
\text { and } \\
\text { Auto* }\end{array}$ \\
\hline Horsley et al., 2007 & Australia & $\mathrm{CC}$ & $\mathrm{HM}$ & 27 & $58.7 \$$ & 48.1 & 32 & $54.6 \$$ & 50 & N/A \\
\hline
\end{tabular}

Abbreviations: N/A, not applicable; HM, hematologic malignancy; CC, case-control; MC, matched-control; Allo, allogeneic; Auto, autologous. *Allogeneic (24 patients each group) and autologous (29 patients each group), " Median, \$ Mean. 


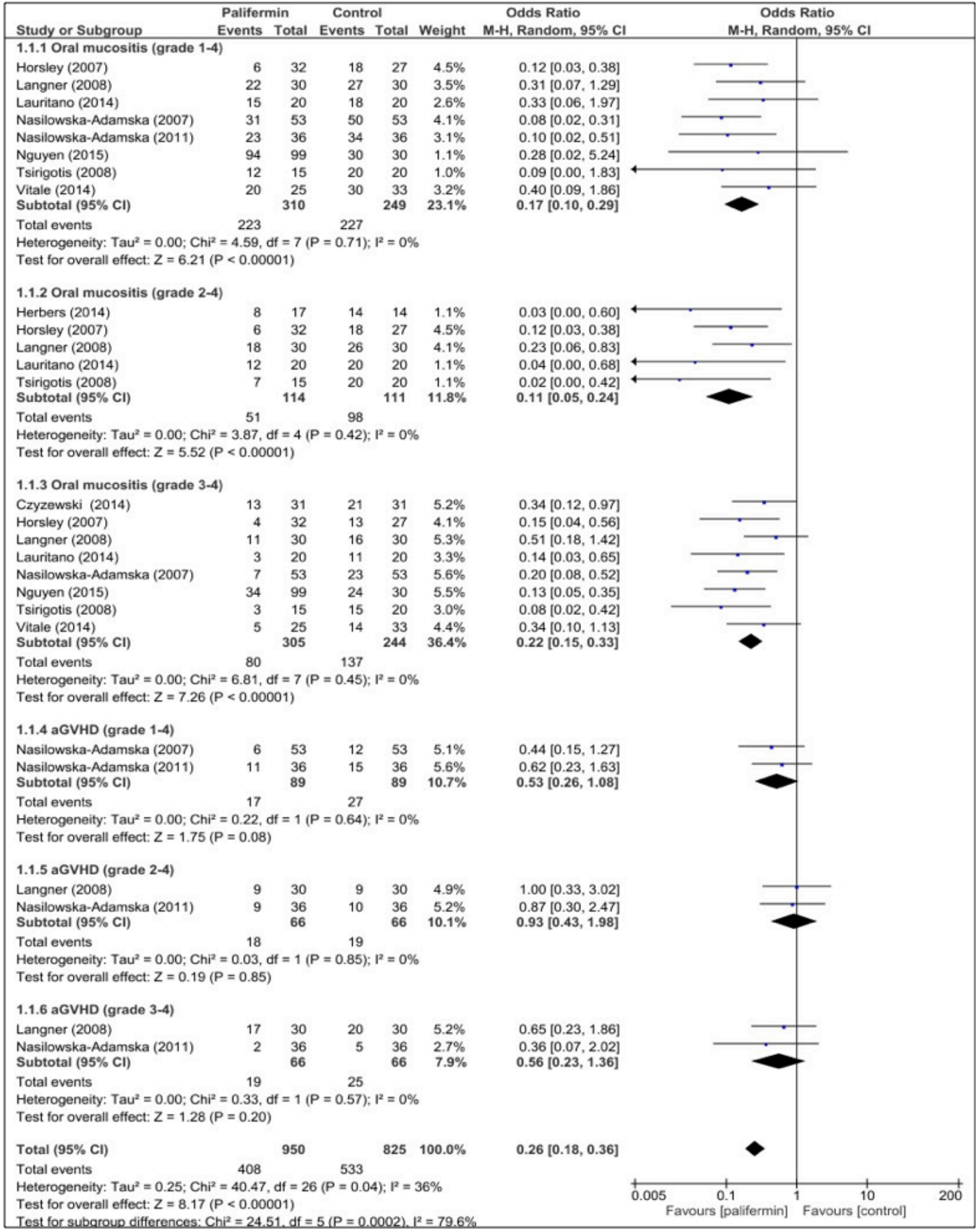

Figure 2. Forest plot of random-effect of OM and aGVHD grades in casecontrol/ matched-control studies after hematopoietic stem cell transplantation. 


\section{Results}

The search in the databases resulted in 117 studies that out of these studies, 32 studies were eligible for assessment. Out of 32 studies, 22 studies were excluded after searching and reading of full-text that the reasons for excluding have been written in Figure 1. Therefore, 10 studies were included in metaanalysis study. One study was commentary study that had complete information for meta-analysis.

\section{Studies characteristics}

Table 1 shows the characteristics of 10 studies included in meta-analysis study. The studies were reported during 2007 to 2015. Three studies were reported in Poland, one in Netherlands, one in Australia, one in Austria, one in Italy, two in the USA, one in Greece, seven were case-control studies and three were matched-control studies. All studies were designed for hematologic malignancy patients that dose of palifermin for each study was $60 \mu \mathrm{g} / \mathrm{kg} /$ day. This metaanalysis included 301 patients in control group and 364 patients in palifermin group. The age (range) and the percentage of the male for each group have been shown in Table 1. Four studies were done undergoing auto-HSCT patients, four studies undergoing allo-HSCT patients, one study didn't report the type of HSCT and one study reported both.

\section{Meta-analysis: The incidence of OM and aGVHD}

Figure 2 shows OR of OM and aGVHD grades in palifermin group compared with control group after HSCT. The pooled subgroup analysis with dichotomous data demonstrated that palifermin was more effective on OM (grade 1-4), (grade $2-4)$ and (grade $3-4)$ with [odds ratio $(O R)=0.17 ; 95 \% \mathrm{Cl}=0.10,0.29 ; p<0.00001$ ], $[O R=0.11 ; 95 \% \mathrm{Cl}=0.05,0.24 ; \mathrm{p}<0.00001]$ and $[\mathrm{OR}=0.22 ; 95 \% \mathrm{Cl}=0.15,0.33 ; \mathrm{p}$ $<0.00001$ ], respectively, but palifermin was not effective on aGVHD (grade 1-4), (grade $2-4$ ) and (grade $3-4$ ) that $[\mathrm{OR}=0.53 ; 95 \% \mathrm{Cl}=0.26,1.08 ; \mathrm{p}<0.08]$, [OR= $0.93 ; 95 \% \mathrm{Cl}=0.43,1.98 ; \mathrm{p}<0.85]$ and $[\mathrm{OR}=0.56 ; 95 \% \mathrm{Cl}=0.23,1.36 ; \mathrm{p}<0.85]$ were respectively, without heterogeneity.

\section{Meta-analysis: The incidence of OM based on the type of HSCT}

The pooled subgroup analysis demonstrated that palifermin was more effective on OM after auto-HSCT and allo-HSCT (Fig. 3). The subgroup analysis showed OM (grade 1-4) had $[\mathrm{OR}=0.13 ; 95 \% \mathrm{Cl}=0.04,0.35 ; p<0.0001]$, (grade 2-4) had $[\mathrm{OR}=0.03 ; 95 \% \mathrm{Cl}=0.00,0.21 ; p=0.0006]$ and (grade $3-4$ ) had $[\mathrm{OR}=0.25$; $95 \% \mathrm{Cl}=0.13,0.48 ; p<0.0001$ ] for auto-HSCT and OM (grade 1-4) had [OR= $0.23 ; 95 \% \mathrm{Cl}=0.11,0.51 ; p=0.0002]$, (grade $2-4$ ) had $[\mathrm{OR}=0.14 ; 95 \% \mathrm{Cl}=0.03$, $0.74 ; p=0.012]$ and (grade $3-4$ ) had $[\mathrm{OR}=0.19 ; 95 \% \mathrm{Cl}=0.08,0.46 ; p=0.0002]$ for allo-HSCT. There was no heterogeneity between estimations for all subgroups, exception for allo-HSCT (grade 2-4) and (grade3-4) that was moderate heterogeneity. 


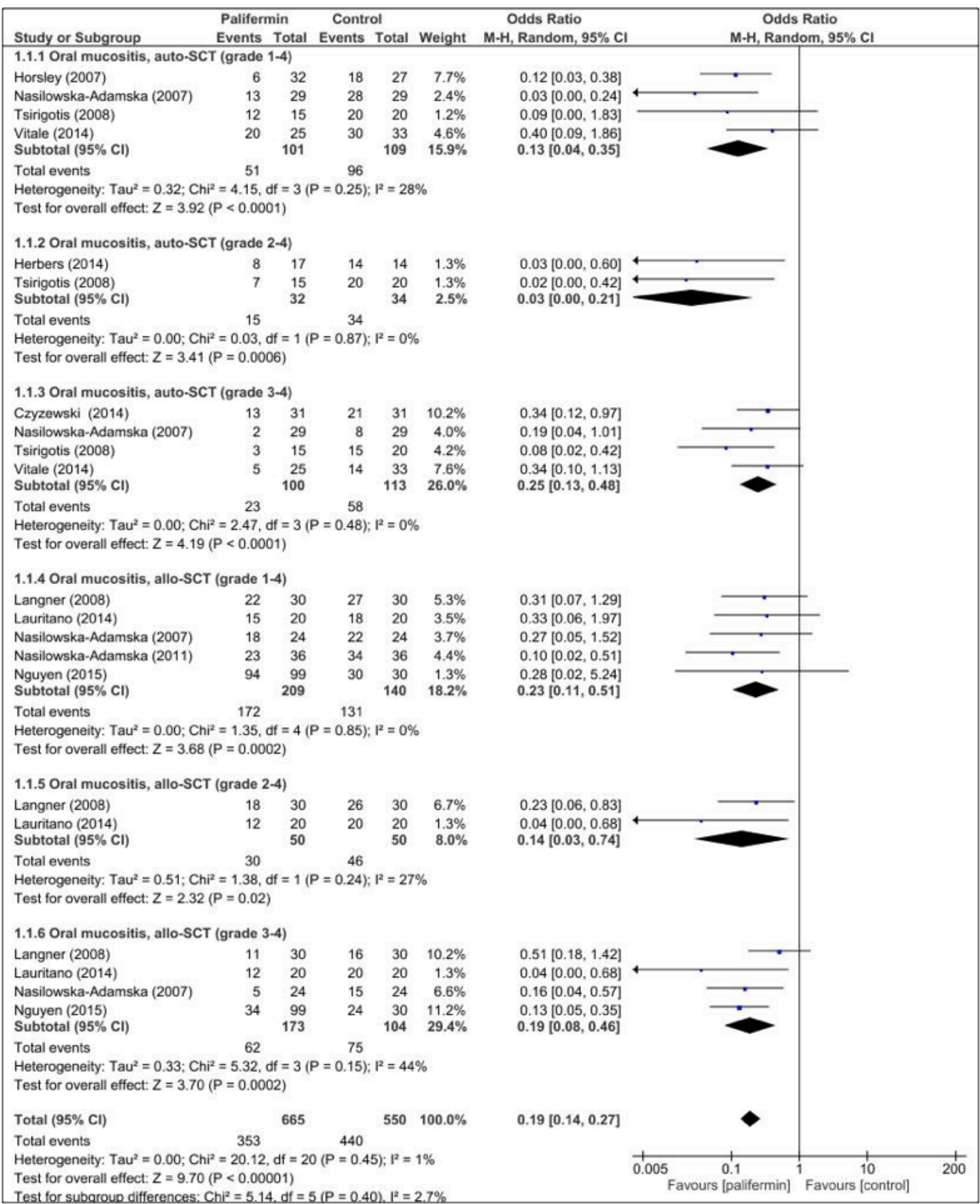

Figure 3. Forest plot of random-effect of OM grades based on the type of stem cell transplant in case-control/ matched-control studies after hematopoietic stem cell transplantation. 


\section{Meta-analysis: The incidence of adverse events}

The comparison of frequency of fever (almost $>38^{\circ} \mathrm{C}$ ) and infection has been included in Figure 4. The pooled subgroup analysis confirmed that the palifermin was more effective on fever $[\mathrm{OR}=0.51 ; 95 \% \mathrm{Cl}=0.29,0.87 ; p=0.01]$, but was not for infection [OR=0.49;95\% $\mathrm{Cl}=0.23,1.06 ; p=0.07]$, without heterogeneity and blood stream infection $[\mathrm{OR}=0.65 ; 95 \% \mathrm{Cl}=0.06,06.68 ; p=$ 0.72] with large heterogeneity.

\begin{tabular}{|c|c|c|c|c|c|c|c|c|c|c|}
\hline \multirow[b]{2}{*}{ Study or Subgroup } & \multicolumn{2}{|c|}{ Palifermin } & \multicolumn{2}{|c|}{ Control } & \multirow[b]{2}{*}{ Weight } & \multirow{2}{*}{$\begin{array}{c}\text { Odds Ratio } \\
\mathrm{M} \cdot \mathrm{H}, \text { Random, } 95 \% \mathrm{Cl}\end{array}$} & \multirow{2}{*}{\multicolumn{4}{|c|}{$\begin{array}{c}\text { Odds Ratio } \\
\mathrm{M}-\mathrm{H}, \text { Random, } 95 \% \mathrm{Cl}\end{array}$}} \\
\hline & Events & Total & Events & Total & & & & & & \\
\hline \multicolumn{11}{|l|}{ 1.1.1 Fever } \\
\hline Czyzewski (2014) & 16 & 31 & 23 & 31 & $12.7 \%$ & $0.37[0.13,1.08]$ & & & & \\
\hline Herbers (2014) & 13 & 23 & 16 & 21 & $8.7 \%$ & $0.41[0.11,1.49]$ & & & & \\
\hline Nasilowska-Adamska (2007) & 41 & 53 & 43 & 53 & $16.2 \%$ & $0.79[0.31,2.04]$ & & & & \\
\hline Vitale (2014) & 8 & 25 & 17 & 33 & $12.4 \%$ & $0.44[0.15,1.31]$ & & & & \\
\hline Subtotal $(95 \% \mathrm{CI})$ & & 132 & & 138 & $49.9 \%$ & $0.51[0.29,0.87]$ & & & & \\
\hline Total events & 78 & & 99 & & & & & & & \\
\hline \multicolumn{11}{|c|}{ Heterogeneity: $\mathrm{Tau}^{2}=0.00 ; \mathrm{Chi}^{2}=1.37, \mathrm{df}=3(\mathrm{P}=0.71) ; \mathrm{I}^{2}=0 \%$} \\
\hline \multicolumn{11}{|c|}{ Test for overall effect: $Z=2.49(P=0.01)$} \\
\hline \multicolumn{11}{|l|}{ 1.1.2 Infection } \\
\hline Czyzewski (2014) & 2 & 31 & 8 & 31 & $5.5 \%$ & $0.20[0.04,1.03]$ & & & & \\
\hline Horsley (2007) & 29 & 32 & 26 & 27 & $2.7 \%$ & $0.37[0.04,3.80]$ & & & & \\
\hline Nasilowska-Adamska (2007) & 17 & 53 & 18 & 53 & $21.6 \%$ & $0.92[0.41,2.06]$ & & & & \\
\hline $\begin{array}{l}\text { Tsirigotis }(2008) \\
\text { Subtotal }(95 \% \mathrm{Cl})\end{array}$ & 4 & $\begin{array}{r}15 \\
131\end{array}$ & 11 & $\begin{array}{r}20 \\
131\end{array}$ & $\begin{array}{r}7.0 \% \\
36.9 \%\end{array}$ & $\begin{array}{l}0.30[0.07,1.26] \\
0.49[0.23,1.06]\end{array}$ & & & & \\
\hline Total events & 52 & & 63 & & & & & & & \\
\hline \multicolumn{11}{|c|}{ Heterogeneity: $\mathrm{Tau}^{2}=0.15 ; \mathrm{Chi}^{2}=3.83, \mathrm{df}=3(\mathrm{P}=0.28) ; \mathrm{I}^{2}=22 \%$} \\
\hline \multicolumn{11}{|c|}{ Test for overall effect: $Z=1.80(P=0.07)$} \\
\hline \multicolumn{11}{|l|}{ 1.1.3 Blood stream infection } \\
\hline Czyzewski (2014) & 0 & 31 & 3 & 31 & $1.6 \%$ & $0.13[0.01,2.61]$ & $\longleftarrow$ & & & \\
\hline Vitale (2014) & 9 & 25 & 9 & 33 & $11.6 \%$ & $1.50[0.49,4.60]$ & & & & \\
\hline Subtotal $(95 \% \mathrm{CI})$ & & 56 & & 64 & $13.2 \%$ & $0.65[0.06,6.68]$ & & & & \\
\hline Total events & 9 & & 12 & & & & & & & \\
\hline \multicolumn{11}{|c|}{ Heterogeneity: $\mathrm{Tau}^{2}=1.80 ; \mathrm{Chi}^{2}=2.34, \mathrm{df}=1(\mathrm{P}=0.13) ; \mathrm{I}^{2}=57 \%$} \\
\hline \multicolumn{11}{|c|}{ Test for overall effect: $Z=0.36(P=0.72)$} \\
\hline Total $(95 \% \mathrm{Cl})$ & & 319 & & 333 & $100.0 \%$ & $0.58[0.39,0.85]$ & & & & \\
\hline Total events & 139 & & 174 & & & & & & & \\
\hline \multicolumn{7}{|c|}{ Heterogeneity: $\operatorname{Tau}^{2}=0.01 ; \mathrm{Chi}^{2}=9.21, \mathrm{df}=9(\mathrm{P}=0.42) ; \mathrm{I}^{2}=2 \%$} & 0.01 & $\begin{array}{lll}0 & 1\end{array}$ & $1 \quad 10$ & 100 \\
\hline \multicolumn{7}{|c|}{ Test for overall effect: $Z=2.78(P=0.005)$} & 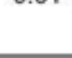 & Favours [palifermin] & Favours [control] & \\
\hline
\end{tabular}

Figure 4. Forest plot of random-effect of adverse events in case-control/ matched-control studies after hematopoietic stem cell transplantation.

\section{Publication bias}

The RevMan 5.3 software was used for publication bias. A funnel plot of each of the pairs of groups compared above was created. If funnel plot was symmetric, it would suggest that the publication bias was minimal and that the results of the present study were credible. The results of the Begg's and Egger's tests revealed that no publication biases existed in terms of oral mucositis (grade 1-4) 
(Fig. 5A), oral mucositis (grade 3-4) (Fig. 5C), oral mucositis (grade 1-4) of autoHSCT (Fig. 5G), oral mucositis (grade 3-4) of auto-HSCT (Fig. 5I), oral mucositis (grade 1-4) of allo-HSCT (Fig. 5J), oral mucositis (grade 3-4) of allo-HSCT (Fig. 5L), fever (Fig. 5M) or infection (Fig. 5N). Regarding aGVHD grade (1-4) (Fig. 5D), aGVHD grade (2-4) (Fig. 5E), aGVHD grade (3-4) (Fig. 5F), oral mucositis (grade 2-4) of auto-HSCT (Fig. 5H), oral mucositis (grade 2-4) of allo-HSCT (Fig. $5 K)$ or blood stream infection (Fig. 50), Begg's tests revealed no publication biases, but Egger's tests could not be performed because only two studies were included. Regarding oral mucositis (grade 3-4) (Fig. 5B), a Begg's test revealed no publication bias, but an Egger's test revealed significant publication bias.

\section{Discussion}

This meta-analysis study assessed OM and aGVHD after HSCT in the patients undergoing palifermin therapy compared with the control group. The results showed that palifermin had an effect on reducing the incidence of $O M$, but not aGVHD. The OM is the most disabling factor in patients with HSCT (Stiff et al., 2006). A case-control study (Nguyen et al., 2015) reported that palifermin associated with a decrease in the severity of $O M$ and duration of overall $O M$ in patients receiving an allo-HSCT with fractionated total body irradiation (TBI) based conditioning. Also, the administration of palifermin during auto-HSCT in children results in a lower incidence of OM (Czyzewski et al., 2014), but a casecontrol in children evaluated that palifermin could not be recommended as a cure for OM (of any grade) due to the variability in the two groups (Kobbe et al., 2010). A randomized-controlled trial by Lucchese et al. (2016) showed a significant reduction in pediatric patients with acute lymphocytic leukemia in the incidence of OM grade 3 and 4 in the palifermin group compared with the control group. There was also a decrease in the degree of severity of $\mathrm{OM}$ in the palifermin group. Horsley et al. (2007) concluded a significant reduction in the incidence of severe $\mathrm{OM}$ in the standard care group compared to the palifermin group (13 versus $48 \%$ ) and also a higher incidence of severe OM in the standard care group compared to the palifermin group. A placebo-controlled, doubleblind, phase III trial by Spielberger et al. (2004) reported palifermin reduced the duration and severity of $\mathrm{OM}$ after intensive chemotherapy and radiotherapy for hematologic malignancies. It has been confirmed that $60 \mu \mathrm{g} / \mathrm{kg} /$ day for 6 doses of palifermin, can effectively reduce the incidence, severity, and duration of $\mathrm{OM}$ and its consequences in TBI- and non-TBI based auto- and allografts without negative influence on transplantation (Radtke et al., 2005; Spielberger et al., 2004; Nasilowska-Adamska et al., 2007; Horsley et al., 2007; Langner et al., 2008; Blazar et al., 2006). A case-control study by Vitale et al. (2014) reported that palifermin prescription did not culminate in a statistically significant decrease in the incidence and grade of $\mathrm{OM}$ or the supportive care required following myeloablative auto-HSCT. 

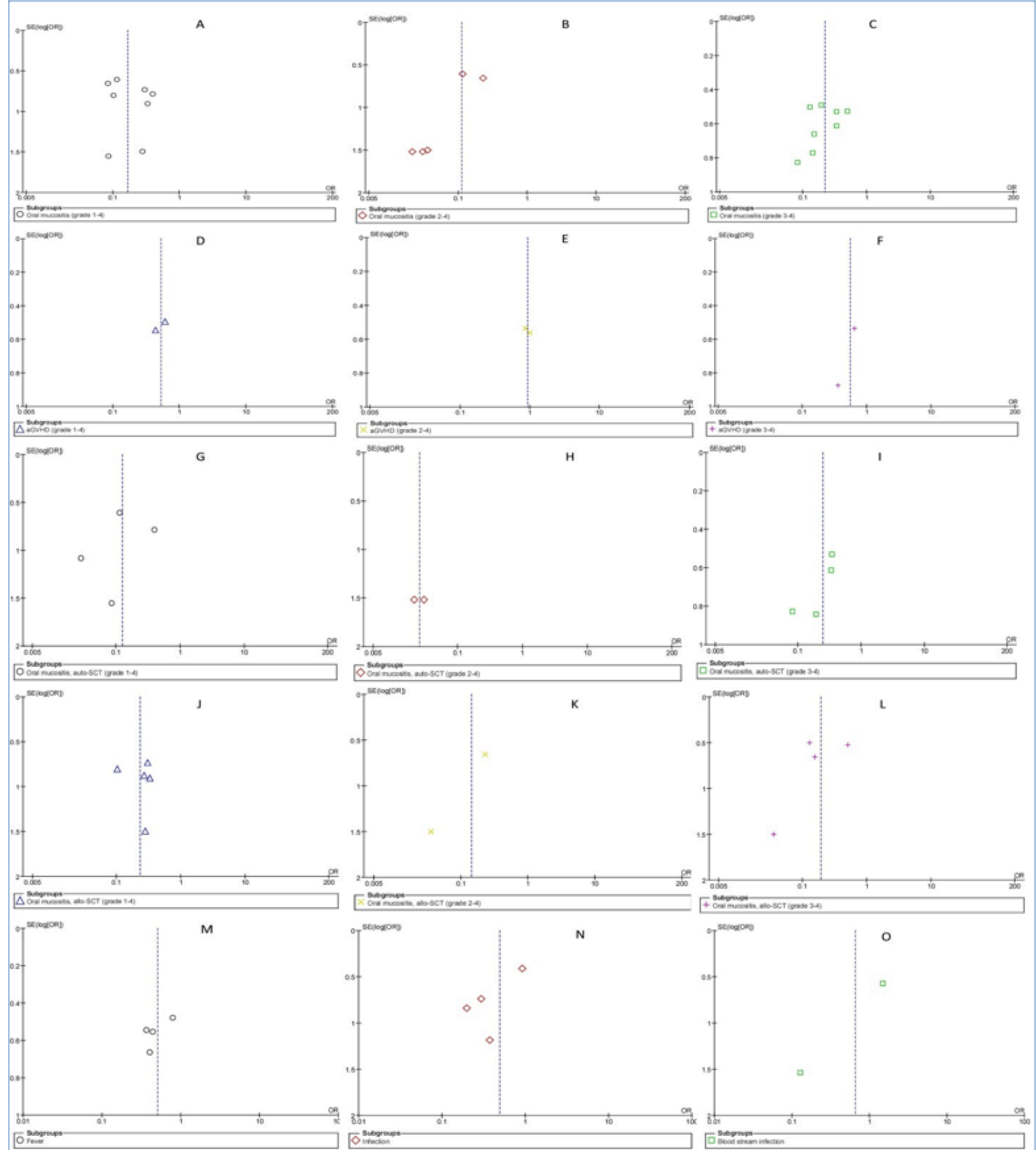

Figure 5. Funnel plot of the incidence of (A) oral mucositis (grade 1-4); (B) oral mucositis (grade 2-4); (C) oral mucositis (grade 3-4); (D) aGVHD grade (1-4); (E) aGVHD grade (2-4); (F) aGVHD grade (3-4); (G) oral mucositis (grade 1-4) of auto-HSCT; $(\mathbf{H})$ oral mucositis (grade 2-4) of auto-HSCT; (I) oral mucositis (grade 3-4) of auto-HSCT; (J) oral mucositis (grade 1-4) of allo-HSCT; (K) oral mucositis (grade 2-4) of allo-HSCT; (L) oral mucositis (grade 3-4) of allo-HSCT; (M) Fever; (N) infection; (O) blood stream infection; in palifermin group compared with control group. 
Tsirigotis et al. (2008) observed a significant decrease in the incidence and severity of $\mathrm{OM}$ in patients treated with keratinocyte growth factor. Palifermin might decrease the incidence, severity, and duration of $\mathrm{OM}$ in high-dose methotrexate (HD-MTX)-based treatment (Schmidt et al., 2008). This metaanalysis of case-control/matched-control studies showed that palifermin reduced significantly the incidence and severity of OM after HSCT in hematologic malignancy patients.

The safety and efficacy profiles of palifermin were assessed by a case-control study on OM and aGVHD in allo-HSCT. There was no significant difference in the incidence of mild or severe aGVHD grades on day 100 after allo-HSCT (Langner et al., 2008) that so Nasilowska-Adamska et al. in a non-randomized and matched-control study (Nasilowska-Adamska et al. 2011), confirmed prescription of palifermin doesn't seem to change the incidence and severity of aGVHD, whereas three other studies indicated that the prescription of palifermin decreases the incidence and severity of aGVHD in allo-HSCT (Blazar et al., 2006; Krijanovski et al., 1999; Panoskaltsis-Mortari et al., 1998). The results of a casecontrol study suggested that the use of palifermin reduces $\mathrm{OM}$ and probably aGVHD after HSCT (Nasilowska-Adamska et al., 2007). The severity of regimeninduced $\mathrm{OM}$ is dependent on the conditioning regimen and not the source of hematopoietic stem cells; thus, the ability of palifermin to reduce the incidence of severe OM in patients with allo-HSCT is not expected to be different than in patients with auto-HSCT (Hensley et al., 2008). Sonis et al. (2004) reported that several factors may affect the incidence of mucositis during HSCT. The most important factors are the diagnosis, type of transplant and type of conditioning regimen. This meta-analysis of case-control studies confirmed that the incidence of OM is the same in auto- and allo-HSCT groups and therefore, type of transplant can't be an important factor in the severity and incidence of OM. Spielberger et al. (2004) stated that in patients with various hematologic cancers, the incidence of severe mucositis was $98 \%$ following conditioning with TBI in combination with high-dose etoposide and cyclophosphamide. In contrast, highdose melphalan was associated with severe mucositis in $20-45 \%$ of patients with multiple myeloma (Grazziutti et al., 2006; Blijlevens et al., 2008). The rate of severe mucositis increased to $80 \%$ when the conditioning regimen was augmented with idarubicin and cyclophosphamide (Fenk et al., 2005). Two studies (Nguyen et al., 2015; Cutler et al., 2005) found the patients who received MTX as part of their GVHD prophylaxis regimen were more to develop severe $\mathrm{OM}(p<0.05)$. This meta-analysis showed that palifermin was not effective on the incidence and severity of aGVHD after HSCT in hematologic cancer patients in case-control studies that due to paucity of studies about the efficacy of palifermin on aGVHD, this result can not be precise. Palifermin could also reduce infections, a complication that after high-dose chemotherapy and auto-HSCT may affect $60-90 \%$ of all cases and that is the cause of deaths in $2-3 \%$ of all treated patients (Gil et al., 2007; Kolbe et al., 1997; Mossad et al., 1996). The results of this meta-analysis showed that palifermin was effective on fever ( $p=$ 0.01 ) and not infection $(p>0.05)$. In case-control/matched-control studies, one 
study confirmed the result of the meta-analysis about fever, but three studies (Czyzewski et al., 2014; Nasilowska-Adamska et al., 2007; Vitale et al., 2014) were disagree with the result. The use of antibiotics given empirically to HSCT recipients can decrease fever thereby lowering the risk of adverse events and the induction of microbial resistance (Herbers et al., 2014). Therefore, antibiotics and topical palliative drugs can help the patients to overcome infections and other unwanted events (Dazzi et al., 2003; Stiff et al., 2001).

\title{
Conclusion
}

In conclusion, although this meta-analysis (the strength: lack of heterogeneity in more analyses) showed that palifermin was associated with reductions in the incidence and severity of $\mathrm{OM}$ and also was effective and safe on OM after alloor auto-HSCT, but did not seem to affect on the incidence and severity of aGVHD, it had several limitations including the numbers of patients in some studies were relatively small; there were variable types of chemotherapy during HSCT in the studies; the age range, the type of HSCT and malignancy were different in the studies. Therefore, due to the above-mentioned limitations and the contradictions of the combined results, studies of large-scale and welldesigned with better exposure evaluations are guaranteed to support the findings of our study and create a higher level of evidence.

\section{Abbreviations}

\author{
aGVHD: Acute GVHD \\ $\mathrm{Cl}$ : Confidence intervals \\ FDA: Food and Drug Administration \\ HD-MTX: High-dose methotrexate \\ HSCT: Hematopoietic Stem Cell Transplantation \\ OM: Oral mucositis \\ OR: Odds ratio \\ TBI: Total body irradiation \\ WHO: World Health Organization
}

\section{Author Contributions}

Conceptualization: MP MS HRM

Data curation: MR MS

Formal analysis: MR MS

Funding acquisition: MP HRM 
Investigation: MP MS

Methodology: MR MS

Project administration: MP HRM

Resources: MR MS

Software: MS

Supervision: MP MR HRM

Validation: MP MR HRM

Visualization: MR MS

Writing - original draft: MS HRM

Writing - review \& editing: MR MP MS HRM

\section{References}

Blazar, B. R., Weisdorf, D. J., Defor, T., Goldman, A., Braun, T., Silver, S., \& Ferrara, J. L. (2006). Phase 1/2 randomized, placebo-control trial of palifermin to prevent graftversus-host disease (GVHD) after allogeneic hematopoietic stem cell transplantation (HSCT). Blood, 108(9), 3216-3222. https://doi.org/10.1182/blood-2006-04-017780

Blijlevens, N., Schwenkglenks, M., Bacon, P., D’Addio, A., Einsele, H., Maertens, J., . . . McCann, S. (2008). Prospective oral mucositis audit: Oral mucositis in patients receiving high-dose melphalan or BEAM conditioning chemotherapy-European Blood and Marrow Transplantation Mucositis Advisory Group. Journal of Clinical Oncology, 26(9), 1519-1525. https://doi.org/10.1200/JC0.2007.13.6028

Cutler, C., Li, S., Kim, H. T., Laglenne, P., Szeto, K. C., Hoffmeister, L., ... Antin, J. H. (2005). Mucositis after Allogeneic Hematopoeitic Stem Cell Transplantation: A Cohort Study of Methotrexate- and Non-Methotrexate-Containing Graft-versus-Host Disease Prophylaxis Regimens. Biology of Blood and Marrow Transplantation, 11(5), 383-388. https://doi.org/10.1016/j.bbmt.2005.02.006

Czyzewski, K., Debski, R., Krenska, A., Wysocki, M., \& Styczynski, J. (2014). Palifermin in children undergoing autologous stem cell transplantation: A matched-pair analysis. Anticancer Research, 34, 7379-7382.

Dazzi, C., Cariello, A., Giovanis, P., Monti, M., Vertogen, B., Leoni, M., . . .. (2003). Prophylaxis with GM-CSF mouthwashes does not reduce frequency and duration of severe oral mucositis in patients with solid tumors undergoing high-dose chemotherapy with autologous peripheral blood stem cell transplantation rescue: A double blind, randomized, placebocontrolled study. Annals of Oncology : Official Journal of the European Society for Medical Oncology, 14(4), 559-563. https://doi.org/ 10.1093/annonc/mdg177

Egger, M., Smith, G., Schneider, M., \& Minder, C. (1997). Bias in meta-analysis detected by a simple, graphical test. BMJ (Clinical Research Ed.), 315(7109), 629-634. https:// doi.org/10.1136/bmj.315.7109.629

Epstein, J. B., Thariat, J., Bensadoun, R. J., Barasch, A., Murphy, B. A., Kolnick, L., . . . Maghami, E. (2012). Oral complications of cancer and cancer therapy: From cancer treatment to survivorship. Cancer J Clin, 62(6), 400-422. https://doi.org/10.3322/caac. $\underline{21157}$ 
Fenk, R., Schneider, P., Kropff, M., Huenerlituerkoglu, A. N., Steidl, U., Aul, C., ... Kobbe, G. (2005). High-dose idarubicin, cyclophosphamide and melphalan as conditioning for autologous stem cell transplantation increases treatment-related mortality in patients with multiple myeloma: Results of a randomised study. British Journal of Haematology, 130(4), 588-594. https://doi.org/10.1111/j.1365-2141.2005.05641.x

Filicko, J., Lazarus, H. M., \& Folmenberg, N. (2003). Mucosal injury in patients undergoing hematopoietic progenitor cell transplantation: New approaches to prophylaxis and treatment. Bone Marrow Transplantation, 31(1), 1-10. https://doi.org/ 10.1038/sj.bmt.1703776

Gil, L., Styczynski, G., \& Komarnicki, M. (2007). Infectious complication In 314 patients after high dose therapy and autologous hematopoietic stem cell transplantation: Risk factor analysis and outcome. Infection, 35(6), 421-427. https://doi.org/10.1007/ s15010-007-6350-2

Grazziutti, M. L., Dong, L., Miceli, M. H., Krishna, S. G., Kiwan, E., Syed, N., ... Anaissie, E. J. (2006). Oral mucositis in myeloma patients undergoing melphalan-based autologous stem cell transplantation: Incidence, risk factors and a severity predictive model. Bone Marrow Transplantation, 38(7), 501-506. https://doi.org/10.1038/sj.bmt. 1705471

Hensley, M. L., Hagerty, K. L., Kewalramani, T., Green, D. M., Meropol, N. J., Wasserman, T. H., . . S Schuchter, L. M. (2008). American Society of Clinical Oncology 2008 Clinical Practice Guideline Update: Use of Chemotherapy and Radiation Therapy Protectants. Journal of Clinical Oncology, 27(1), 127-145. https://doi.org/10.1200/JCO. $\underline{2008.17 .2627}$

Herbers, A. H., van der Velden, W. J., de Haan, A. F., Donnelly, J. P., \& Blijlevens, N. M. (2014). Impact of palifermin on intestinal mucositis of HSCT recipients after BEAM. Bone Marrow Transplantation, 49(1), 8-10. https://doi.org/10.1038/bmt.2013.118

Hołowiecki, J. (2008). Indications for hematopoietic stem cell transplantation. Polskie Archiwum Medycyny Wewnetrznej, 118, 658-663.

Horsley, P., Bauer, J. D., Mazkowiack, R., Gardner, R., \& Bashford, J. (2007). Palifermin improves severe mucositis, swallowing problems, nutrition impact symptoms, and length of stay in patients undergoing hematopoietic stem cell transplantation. Supportive Care in Cancer, 15(1), 105-109. https://doi.org/10.1007/s00520-006-0105-y Jilani, S., Kanaan, Z., Agarwal, R., Tageja, N., \& Abidi, M. H. (2014). Palifermin for Prevention of Oral Mucositis in Hematological Malignancies: Present Position and Future Perspectives. Austin J Cancer Clin Res, 1, 1010.

Krijanovski, O. I., Hill, G. R., Cooke, K. R., Teshima, T., Crawford, J. M., Brinson, Y. S., \& Ferrara, J. L. (1999). Keratinocyte growth factor separates graft-versus-leukemia effects from graft-versus-host disease. Blood, 94, 825-831.

Kobbe, G., Bruns, I., Schroeder, T., Czibere, A., Warnecke, J., Hieronimus, N., . . Fenk, R. (2010). A 3-day short course of palifermin before HDT reduces toxicity and need for supportive care after autologous blood stem-cell transplantation in patients with multiple myeloma. Annals of Oncology: Official Journal of the European Society for Medical Oncology, 21(9), 1898-1904. https://doi.org/10.1093/annonc/mdq059

Kolb, H. J. (2017). Hematopoietic stem cell transplantation and cellular therapy. HLA, 89(5), 267-277. https://doi.org/10.1111/tan.13005

Kolbe, K., Domkin, D., Derigs, H. G., Bhakdi, S., Huber, C., \& Aulitzky, W. E. (1997). Infectious complications during neutropenia subsequent to peripheral blood stem cell 
transplantation. Bone Marrow Transplantation, 19(2), 143-147. https://doi.org/10.1038/ sj.bmt.1700621

Langner, S., Staber, P., Schub, N., Gramatzki, M., Grothe, W., Behre, G., ... Neumeister, P. (2008). Palifermin reduces incidence and severity of oral mucositis in allogeneic stemcell transplant recipients. Bone Marrow Transplantation, 42(4), 275-279. https://doi.org/ 10.1038/bmt.2008.157

Lauritano, D., Petruzzi, M., Di Stasio, D., \& Lucchese, A. (2014). Clinical effectiveness of palifermin in prevention and treatment of oral mucositis in children with acute lymphoblastic leukaemia: A case-control study. International Journal of Oral Science, 6(1), 27-30. https://doi.org/10.1038/ijos.2013.93

Lucchese, A., Matarese, G., Ghislanzoni, L. H., Gastaldi, G., Manuelli, M., \& Gherlone, E. (2016). Efficacy and effects of palifermin for the treatment of oral mucositis in patients affected by acute lymphoblastic leukemia. Leukemia \& Lymphoma, 57(4), 820-827. https://doi.org/10.3109/10428194.2015.1081192

Mossad, S. B., Longworth, D. L., Goormastic, M., Serkey, J. M., Keys, T. F., \& Bolwell, B. J. (1996). Early infectious complications in autologous bone marrow transplantation: A review of 219 patients. Bone Marrow Transplantation, 18, 265-271.

Nasilowska-Adamska, B., Rzepecki, P., Manko, J., Czyz, A., Markiewicz, M., Federowicz, I., ... Marianska, B. (2007). The influence of palifermin (Kepivance) on oral mucositis and acute graft versus host disease in patients with hematological diseases undergoing hematopoietic stem cell transplant. Bone Marrow Transplantation, 40(10), 983-988. https://doi.org/10.1038/sj.bmt.1705846

Nasilowska-Adamska, B., Szydlo, R., Rzepecki, P., Czyz, A., Tomaszewska, A., Markiewicz, M., . . Jedrzejczak, W. W. (2011). Palifermin does not influence the incidence and severity of GvHD nor long-term survival of patients with hematological diseases undergoing HSCT. Annals of Transplantation, 16(4), 47-54. https://doi.org/10.12659/ AOT.882218

Nguyen, D. T., Shayani, S., Palmer, J., Dagis, A., Forman, S. J., Epstein, J., \& Spielberger, R. (2015). Palifermin for prevention of oral mucositis in allogeneic hematopoietic stem cell transplantation: A single-institution retrospective evaluation. Supportive Care in Cancer, 23(11), 3141-3147. https://doi.org/10.1007/s00520-015-2688-7

Panoskaltsis-Mortari, A., Lacey, D. L., Vallera, D. A., \& Blazar, B. R. (1998). Keratinocyte growth factor administered before conditioning ameliorates graft-versus-host disease after allogeneic bone marrow transplantation in mice. Blood, 92, 3960-3967.

Radtke, M. L., \& Kolesar, J. M. (2005). Palifermin (Kepivance) for the treatment of oral mucositis in patients with hematologic malignancies requiring hematopoietic stem cell support. Journal of Oncology Pharmacy Practice, 11(3), 121-125. https://doi.org/ 10.1191/1078155205jp159oa

Schmidt, E., Thoennissen, N. H., Rudat, A., Bieker, R., Schliemann, C., Mesters, R. M., . . Berdel, W. E. (2008). Use of palifermin for the prevention of high-dose methotrexateinduced oral mucositis. Annals of Oncology : Official Journal of the European Society for Medical Oncology, 19(9), 1644-1649. https://doi.org/10.1093/annonc/mdn179

Spielberger, R., Stiff, P., Bensinger, W., Gentile, T., Weisdorf, D., Kewalramani, T., . . . Emmanouilides, C. (2004). Palifermin for oral mucositis after intensive therapy for hematologic cancers. The New England Journal of Medicine, 351(25), 2590-2598. https://doi.org/10.1056/NEJMoa040125 
Sonis, S., \& Clark, J. (1991). Prevention and management of oral mucositis induced by antineoplastic therapy. Oncology (Williston Park, N.Y.), 5, 11-18.

Sonis, S. T., Elting, L. S., Keefe, D., Peterson, D. E., Schubert, M., Hauer-Jensen, M., . . . Rubenstein, E. B. (2004). Perspectives on cancer therapy-induced mucosal injury: Pathogenesis, measurement, epidemiology, and consequences for patients. Cancer, 100(S9), 1995-2025. https://doi.org/10.1002/cncr.20162

Stiff, P. J., Erder, H., Bensinger, W. I., Emmanouilides, C., Gentile, T., Isitt, J., . . . Spielberger, R. (2006). Reliability and validity of a patient selfadministered daily questionnaire to assess impact of oral mucositis (OM) on pain and daily functioning in patients undergoing autologous hematopoietic stem cell transplantation (HSCT). Bone Marrow Transplantation, 37(4), 393-401. https://doi.org/10.1038/sj.bmt.1705250

Stiff, P. (2001). Mucositis associated with stem cell transplantation: Current status and innovative approaches to management. Bone Marrow Transplantation, 27, S3-S11. https://doi.org/10.1038/sj.bmt.1702863

Tsirigotis, P., Triantafyllou, K., Girkas, K., Giannopoulou, V., Ioannidou, E., Chondropoulos, S., ... Dervenoulas, J. (2008). Keratinocyte growth factor is effective in the prevention of intestinal mucositis in patients with hematological malignancies treated with high-dose chemotherapy and autologous hematopoietic SCT: A videocapsule endoscopy study. Bone Marrow Transplantation, 42(5), 337-343. https:// doi.org/10.1038/bmt.2008.168

Vitale, K. M., Violago, L., Cofnas, P., Bishop, J., Jin, Z., Bhatia, M., . . Satwani, P. (2014). Impact of palifermin on incidence of oral mucositis and healthcare utilization in children undergoing autologous hematopoietic stem cell transplantation for malignant diseases. Pediatric Transplantation, 18(2), 211-216. https://doi.org/10.1111/petr.12192 Woo, S. B., Sonis, S. T., Monopoli, M. M., \& Sonis, A. L. (1993). A longitudinal study of oral ulcerative mucositis in bone marrow transplant recipients. Cancer, 72(5), $1612-$ 1617. https://doi.org/10.1002/1097-0142(19930901)72:53.0.CO;2-O 